\title{
Uma Abordagem para Apoio em Laboratórios Computacionais em Escolas Públicas de Ensino Infantil
}

\author{
Lucas Micol Policarpo $^{1}$, Gabriel Tobias Fuhr ${ }^{1}$, Giovani R. Librelotto ${ }^{1}$ \\ ${ }^{1}$ Curso de Ciência da Computação \\ Universidade Federal de Santa Maria (UFSM) - Santa Maria, RS - Brasil \\ \{lmpolicarpo, gtfuhr, librelotto\}@inf.ufsm.br
}

\begin{abstract}
In this article we propose a case study and the analysis of its results. It consists of an intervention on the Municipal School of Early Childhood Education Vila Jardim in Santa Maria, on the state of Rio Grande do Sul. The main objective was to introduce computational knowledge to needy children and also to stimulate their creativity and interest in computing. The study took place inside the school itself, with 17 students from five to six years of age, at the computer lab. In order to make it possible, maintenance was carried out on the equipment and changes in the layout of the room had to be made in order to provide an environment conducive to the construction of learning for the children.
\end{abstract}

Resumo. Neste artigo propõe-se um estudo de caso e a análise de seus resultados, baseado em uma intervenção com alunos da Escola Municipal de Educação Infantil Vila Jardim de Santa Maria, RS. O objetivo principal foi introduzir o saber computacional à crianças carentes e também o de estimular a sua criatividade e interesse pela computação. O estudo ocorreu dentro da própria escola, com 17 alunos de cinco a seis anos de idade, no laboratório de informática. Para viabilizá-lo, foram realizadas manutenções nos equipamentos e mudanças no leiaute da sala a fim de proporcionar às crianças um ambiente propício à construção de aprendizagem.

\section{Introdução}

A Informática vem se tornando presente em praticamente todas as atividades do cotidiano. Cada vez mais as pessoas utilizam da tecnologia no seu dia-a-dia, muitas vezes sequer percebem. Há tempos que buscou-se aliar a tecnologia à educação. Com a evolução tecnológica fazendo parte dos diversos setores da sociedade, considerou-se que a escola também devesse fazer parte deste processo de informação globalizada [Medeiros 2011].

Com a introdução das novas tecnologias de comunicação no ambiente escolar surgem novos desafios para a escola e para o professor. O principal desafio é de ordem social. A instituição escolar tem sido observada como um setor da sociedade mais tradicional do que inovador. Enquanto todos os setores da sociedade modernizam-se, a escola permanece sem grandes alterações na sua forma de produzir conhecimento [Correia 2013]. A informática na educação vem com o intuito de solucionar problemas de aprendizado dos alunos, trazendo novas formas de raciocínio para que o estudante possa posicionar-se como o construtor do próprio conhecimento.

Esse conservadorismo acaba dificultando o desenvolvimento lógicocomputacional dos alunos, além do manuseio com tecnologia [Costa 2016]. Moran 
acredita que as tecnologias auxiliam a educação no sentido de que criam novos espaços de comunicação e informação. O objetivo principal deve ser sempre o desenvolvimento do aluno como ser integral, capaz de conviver de forma saudável na sociedade. Aprender, para Moran, vai além de realizar buscas na Internet. Para Moran, educar é criar possibilidades para alunos e professores transformarem suas vidas em processos de constantes aprendizagens. É colaborar para que o aluno construa a sua trajetória pessoal. O aprendizado dá-se em todos os espaços que este ser atua, ele aprende através de tudo o que lê ou escuta, no convívio com as pessoas, ou seja, através de todas as suas experiências [Moran 2009].

Este projeto foi criado com o intuito de introduzir o saber computacional à crianças do Ensino Infantil, com o objetivo de despertar o pensamento computacional. Para isso, antes do contato com o mundo digital, as crianças realizaram atividade de computação desplugada, introduzindo o conhecimento lógico nos alunos. A metodologia apresentada determina uma sequência de passos, que incluem à aplicação de conteúdos relacionados diretamente a softwares, através de brincadeiras, atividades e jogos, seja tanto de maneira desplugada quanto digital. Associada a esse último conteúdo, está o manuseio do mouse e do teclado. Posto isso, entende-se que o projeto deve cumprir seu objetivo principal que é o de proporcionar o contato inicial da criança com a computação no ambiente escolar e de que através deste contato o aluno tenha a oportunidade de desenvolver seu raciocínio lógico-cognitivo, possibilitando ao estudante a capacidade de solucionar problemas, facilitar as suas atividades diárias e da escola.

Este trabalho está estruturado da seguinte forma: a Seção 2 apresenta alguns trabalhos relacionados e suas vantagens e desvantagens para esta abordagem. Por sua vez, a Seção 3 descreve a metodologia proposta, basicamente como abordou-se o tema e a seleção de materiais utilizados. A seção 4 apresenta o caso de estudo, com a EMEI Vila Jardim. Por fim, nas seções 5 e 6, apresenta-se respectivamente os resultados e a conclusão.

\section{Trabalhos relacionados}

Um dos principais referenciais para este trabalho é o artigo "Ensino de Computação na Educação Básica" [SBC 2018] que traz uma boa visão geral sobre a importância da computação tanto no ensino quanto no desenvolvimento lógico.

Fora isso também foi utilizado o material da CS Unplugged [Bell 2011] que é uma coleção de atividades gratuitas de aprendizado que ensinam Ciência da Computação por meio de jogos envolventes e quebra-cabeças que usam cartões, barbantes e giz de cera. Este material foi desenvolvido pela Universidade de Canterbury da Nova Zelândia e traz um sistema muito simples e abrangente de atividades para crianças.

Também como material auxiliar, foi utilizada a tese de Doutorado de Christian Brackmann [Brackmann 2017], esta que tem total foco em ensino de computação para crianças e possui atividades de ensino práticas e algumas com personagens do cotidiano brasileiro, como personagens da turma da Mônica, por exemplo, que chamam atenção das crianças.

Podemos afirmar que estes trabalhos possuem características semelhantes, visto que trazem algumas brincadeiras parecidas. Porém, o que nos fez escolher estas duas 
abordagens para o mesmo assunto foi o fato de que uma foi desenvolvida na Nova Zelândia e a outra no Brasil, e com isto, poderia-se determinar qual dos materiais e quais das brincadeiras são mais adaptáveis para esta abordagem em Escola Pública de Ensino Infantil, onde a realidade pode ser diferente de uma escola estrangeira ou de uma escola particular no próprio país.

\section{Metodologia}

Foram adotados dois métodos para este trabalho, o primeiro seria explorar a computação desplugada e o segundo a computação em jogos. Nos dois casos trabalharíamos com crianças pequenas 6 anos, em média. Então procuramos as melhores abordagens para o assunto.

\subsection{Computação desplugada}

A computação desplugada é uma das áreas mais exploradas de ensino de computação para crianças. Tratam-se de jogos e brincadeiras que podem ser realizadas no papel e caneta, cartolina, ou até mesmo com objetos recicláveis. Essas brincadeiras têm como objetivo estimular o raciocínio e a lógica das crianças, uma vez que estes jogos tentam simular de maneira didática o funcionamento do computador.

Desta área, destacam-se o livro "Ensinando ciência da computação sem o uso do computador" [Bell 2011] e a tese de Doutorado de Christian Brackmann [Brackmann 2017]. Ambas foram elaboradas com um embasamento teórico adequado e apresentam bons pontos e atividades para serem desenvolvidas. Entretanto ambas possuíam uma grande diversidade de alternativas de conteúdo para ser abordado. Por isso, selecionou-se alguns dos conteúdos nos dois casos, levando em conta a idade das crianças neste ambiente de desenvolvimento. Sendo assim, selecionou-se atividades com uma idade mínima recomendada de 5 anos e a facilidade da realização da atividade por parte da escola. Do livro [Bell 2011], selecionou-se:

- Contando os Pontos - Números Binários: A atividade consiste no aprendizado de maneira didática, de como funciona os números dentro computador, ensinando os participantes a contarem em binário e saberem descobrir qual número decimal que um binário dado representa.

- Colorindo com Números - Representação de Imagens: Esta atividade tem como objetivo ensinar como o computador armazena uma imagem, trabalhando com uma matriz em branco e formando as imagens a partir de instruções passadas para pintar quadrados.

- Seguindo Instruções - Linguagens de Programação: Nesse exercício um estudante deve receber uma imagem e tentar descrever ela para a turma, e estes devem tentar reproduzir a partir da descrição do aluno a mesma imagem. Com essa atividade, os alunos vão desenvolvendo uma "linguagem"que os auxilia na tarefa, muito similar a forma como funciona a programação.

Da tese [Brackmann 2017], selecionou-se:

- Boneca de Papel: O jogo consiste em saber qual é a melhor roupa para ser colocada na boneca, cada roupa corresponde com uma condição que deve ser dita antes. Por exemplo, se estiver chovendo coloque $\mathrm{X} 1, \mathrm{X} 2$ e $\mathrm{X} 3$ peças de roupas, se não, coloque Y1,Y2,Y3. X e Y são cartões com ilustrações, como por exemplo $\mathrm{X} 1$ é um óculos de sol e X2 um biquíni. 
- Decomposição: O jogo consiste em levar um problema, como plantar uma árvore, e fazer com que a criança crie pequenos problemas para serem resolvidos em uma ordem para que a árvore seja plantada. O problema é ilustrado com uma imagem e logo do lado possui as linhas para a criança escrever as ações necessárias.

- Mônica caminhos: O jogo consiste em saber qual é a melhor rota para chegar de um personagem até o outro, como por exemplo, qual a melhor rota para a Mônica encontrar a Magali. No meio do mapa possui um rio, fazendo com que tenham que levar até a ponte e depois até o personagem. Esse jogo exige mais da criança.

\subsection{Computação com Jogos}

A ideia de trabalhar com jogos surge com o objetivo de desenvolver o raciocínio lógico, coordenação motora e criatividade das crianças. Para esta abordagem, utilizou-se a distribuição Linux Educacional 5.0 [UFPR 2012] disponibilizada pela UFPR (Universidade Federal do Paraná), o qual é um sistema operacional totalmente focado no aprendizado de crianças.

Deste sistema selecionou-se os jogos que melhor se adequavam ao contexto deste trabalho, os quais são:

- Palavras Cadentes: Jogo que consiste em digitar as palavras que aparecem na parte de cima da tela antes que elas cheguem no final da tela. Este jogo ajuda a desenvolver a formação de palavras, assim como a agilidade e língua portuguesa.

- TuxMath: Similar ao Palavras Cadentes, o jogador não pode deixar as contas chegarem no final da tela. Bom para praticar matemática e lógica. Ideal para alunos do fundamental que estão aprendendo a fazer contas.

- TuxPaint: Programa de desenho similar ao Paint do Windows, ideal para os alunos desenvolverem a criatividade praticando desenho.

- Ktuberling: Mais conhecido como "Jogo do Senhor Batata", consiste em um jogo de customização de personagem, onde a criança pode explorar a sua imaginação para desenvolver a sua criatividade personalizando as diferentes roupas, características e acessórios disponíveis para o "Senhor Batata".

- Gcompris: Jogo que contribui com a coordenação motora da criança, assim como auxilia com a familiarização do teclado e do mouse, este jogo contém vários mini jogos que consistem em atividades a serem realizadas, como montar um quebracabeça, ou aprender como funcionam as horas no relógio.

\subsection{Incorporação a instituição}

Para dar início a realização das atividades, é preciso haver a comunicação entre os participantes do projeto e a equipe da Escola a ser ajudada. Com o interesse da Escola em participar do projeto, o grupo necessita elaborar também um plano de reforma computacional, o qual pode ser definido nos seguintes passos: Contato Inicial, Reforma, Capacitação para professores e Acompanhamento.

Contato inicial: a primeira etapa é analisar o material disponível na escola e contabilizar todo tipo de equipamento que pode ser útil no desenvolvimento da atividade.

Reforma: com um levantamento prático dos materiais, o grupo faz uma reforma nos computadores (caso seja necessário). A reforma é feita através da limpeza dos computadores, verificação dos cabos, teste de peças e a eventual troca de peças estragadas. 
No final dessa etapa, os computadores são formatados e é instalado o sistema operacional Linux Educacional 5.0, a escolha do sistema operacional pode ser feita em conjunto a equipe da Escola.

Capacitação para os professores: nesta etapa, os responsáveis devem se reunir com os professores da escola, explicar as atividades descritas nas seções 3.1 e 3.2 deste trabalho, e fazer com que os professores pratiquem as atividades, de forma que estes primeiramente se familiarizem com as brincadeiras antes de colocarem em prática. Essa integração dos professores é muito importante para um melhor aprendizado das crianças.

Atividades desplugadas: Após a capacitação dos professores é realizada uma atividade desplugada com as crianças da escola. Nessa atividade são selecionados alguns dos jogos citados na seção 3.4, que são trabalhados junto aos professores para estimular o contato das crianças e dos professores com as brincadeiras propostas.

Jogos Digitais: Assim como nas atividades desplugadas esta parte do planejamento consiste em aproximar os professores e alunos dos jogos selecionados, desenvolvendo alguns dos jogos selecionados com as crianças.

Acompanhamento: por fim, durante a realização da atividade, o grupo deve manter-se responsável e ativo junto à escola, auxiliando em manutenções e outras necessidades computacionais, assim como deve prestar acompanhamento técnico caso requisitado.

Para melhor adaptação às escolas, todo material reunido é disponibilizado aos professores. Também recomenda-se que, pelo menos uma vez na semana, alguma das atividades seja realizada. Vale ressaltar que depende da instituição alvo colocar em prática as atividades propostas, assim como manter ativa as práticas computacionais nas aulas. Durante toda realização da atividade o grupo que efetivar a ação, deve manter-se responsável e ativo junto a escola, auxiliando em manutenções ou qualquer outra necessidade computacional.

\section{Caso de Estudo: Escola Municipal de Educação Infantil Vila Jardim}

Nesta seção apresentam-se as discussões descritas nas seções anteriores de forma a ser aplicada em uma escola infantil. O primeiro passo foi o contato inicial com a escola parceira, a Escola Municipal de Ensino Infantil Vila Jardim de Santa Maria, RS. O contato inicial foi com a diretora encarregada da escola, onde foram explicadas as atividades a serem desenvolvidas. A escola está situada em uma comunidade em vulnerabilidade social e recebe doações dos moradores locais que ajudam a manter a escola em funcionamento. Os alunos variam de 3 a 6 anos, sendo que praticamente todos não possuem contato com computadores em suas residências.

Nesta escola, em particular, trabalhou-se com uma amostra de 17 alunos, onde todos já sabiam ler números e identificar letras e alguns conseguiam compreender palavras. Em geral, notou-se que nenhum dos alunos sabiam utilizar o computador, de forma que todos tiveram que aprender a mexer com mouse, assim como digitar em um teclado.

\subsection{Primeiro contato e reformas}

Inicialmente, verificou-se o que a escola possuía de material disponível, sejam computadores, monitores, teclados, mouses, entre outros. O material estava em bom estado, porém 
parado por falta de manutenção e de pessoal qualificado, como mostra a Figura 1. Com isso, realizou-se uma reforma no material: foram trocados teclados antigos e mouses estragados, os computadores foram limpados por dentro e a sala reorganizada para melhor manuseio das máquinas, o que pode ser visto na Figura 2. Como os computadores contavam com o sistema operacional Windows XP, eles foram formatados para a instalação do Linux Educacional 5.0. Assim, foi concluída a manutenção dos computadores e foi iniciado a segunda parte do projeto.
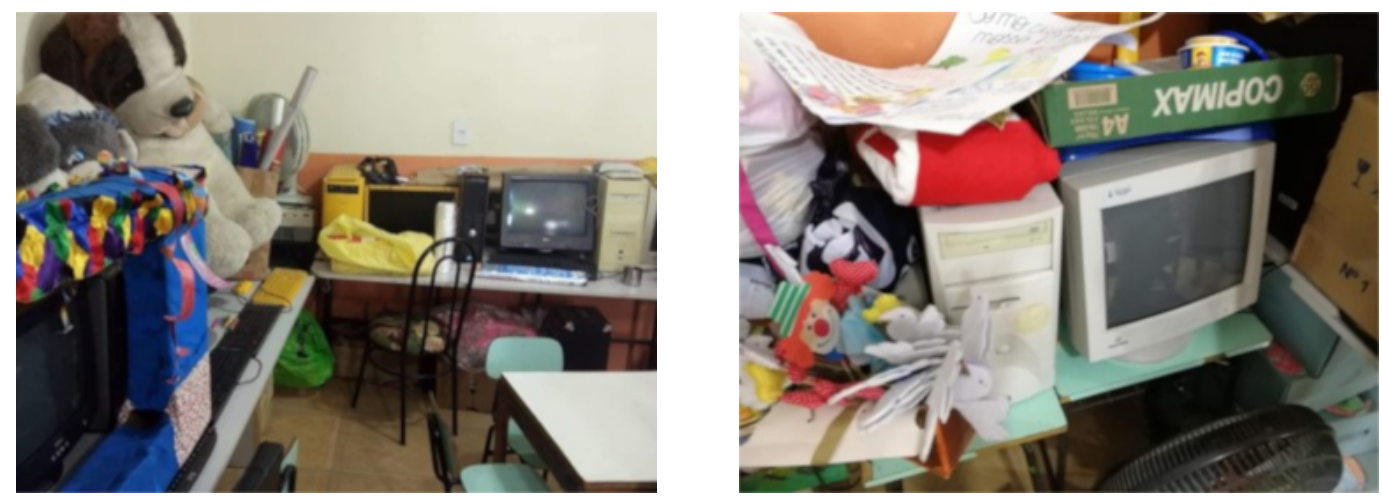

Figura 1. Antes da reforma
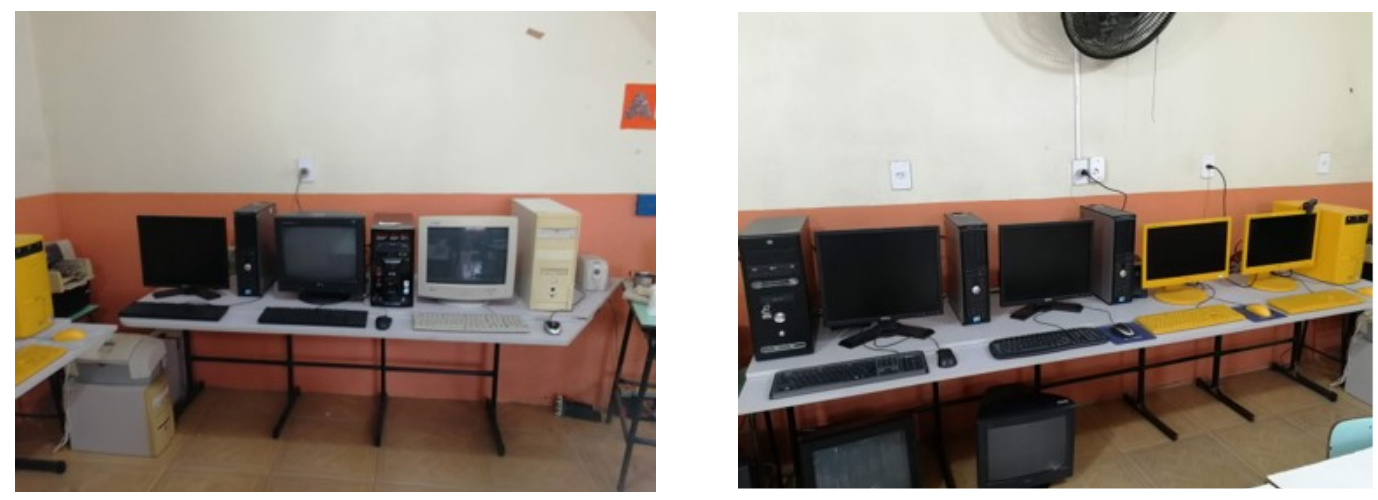

Figura 2. Após reforma

\subsection{Capacitação para os Professores}

A continuação do projeto seria realizar um minicurso para os professores sobre a utilização das ferramentas educativas, após isso, a escola e suas eventuais necessidades relacionadas à computação serão atendidas. Tivemos um ótimo resultado inicial e pretendemos continuar com a atividade prática em diante.

1 - Introdução ao linux educacional (ligar e desligar computadores, abertura e fechamento de programas, localizar a atividade escolhida para a aula).

2 - Treinamento dos jogos e atividades selecionados (uso das ferramentas escolhidas, prática destas para que os professores tenham aptidão.

\subsection{Atividade desplugada}

Antes de iniciar a introdução ao mundo digital, foi realizado primeiramente atividades de computação desplugada. Essas atividades, como previamente comentado, não fazem 
o uso do computador, mas tem como objetivo incentivar o desenvolvimento lógico dos alunos. No primeiro caso de teste foi decidido seguir com dois exercícios selecionados do material da CS Unplugged: o Contando os Pontos e o Colorindo com Números.

A primeira atividade escolhida foi a de Números Binários, onde foi trabalhado como contar em binários e a forma como o número fica representado, tudo com papel e cartão, da maneira mais abstrata possível. Após as explicações e alguns exercícios, colocou-se na mesa um número em binário, representado da seguinte forma como descreve a Figura 3.

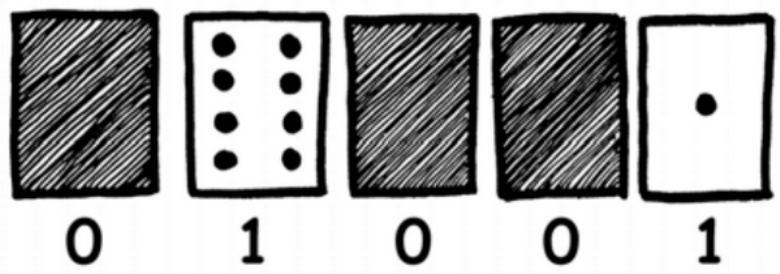

Figura 3. Representação utilizada para números binários

Os alunos foram aprendendo ao longo da atividade e começaram a conversar entre si para tentar descobrir qual número que estava sendo representado, muitos foram ajudando uns aos outros. Por fim, eles tiveram um desempenho muito bom na primeira atividade.

Passou-se então para uma atividade um pouco mais difícil: A brincadeira da representação de imagens no computador. De início, foi feita uma roda para que todos alunos pudessem participar e fomos pintando um exemplo todos juntos. Entretanto, a maioria se atrapalhou durante a atividade, o que permitiu entender que o exercício é avançado demais para a idade dos alunos desta turma. Como percebemos que a atividade estava frustrando as crianças que tentavam acertar, mas acabavam errando (assim como muitas não conseguiam seguir o passo a passo para o desenho), foi permitido que elas pintassem de forma livre e depois tentassem reproduzir o mesmo desenho no computador.

\subsection{Jogos digitais}

Após as brincadeiras desplugadas, partiu-se para o computador, onde as crianças foram separadas em três grupos com 4 integrantes e um com 5. Permitiu-se utilizar os computadores de maneira livre para aprender a utilizar o mouse e ver como funciona o teclado. Nessa primeira parte, notou-se que muitos tentavam mover o ponteiro na tela arrastando o dedo em cima do mouse (como no touchscreen dos celulares). Os grupos então foram revezando os membros para determinar quem utilizava o computador, até que todos tenham aprendido a utilizar o mouse. Após isso, foi dado início aos jogos selecionados: o Ktuberling, Palavras Cadentes e TuxPaint.

O primeiro foi o Ktuberling, com intuito de estimular a criatividade. Permitiu-se que cada aluno de cada grupo possa criar seu "Senhor Batata". As criança se divertiram e ajudaram uns aos outros a escolherem as roupas e acessórios de seu boneco.

Depois foram abertos os jogos Palavras Cadentes e TuxPaint nos computadores. Os grupos foram desfeitos e deixamos as crianças se dividirem na atividade que gostariam 
de participar. A divisão foi de 7 crianças para o Palavras Cadentes e 10 para o TuxPaint. A Figura 4 demonstra a atenção das crianças na realização da atividade por um dos membros do grupo.

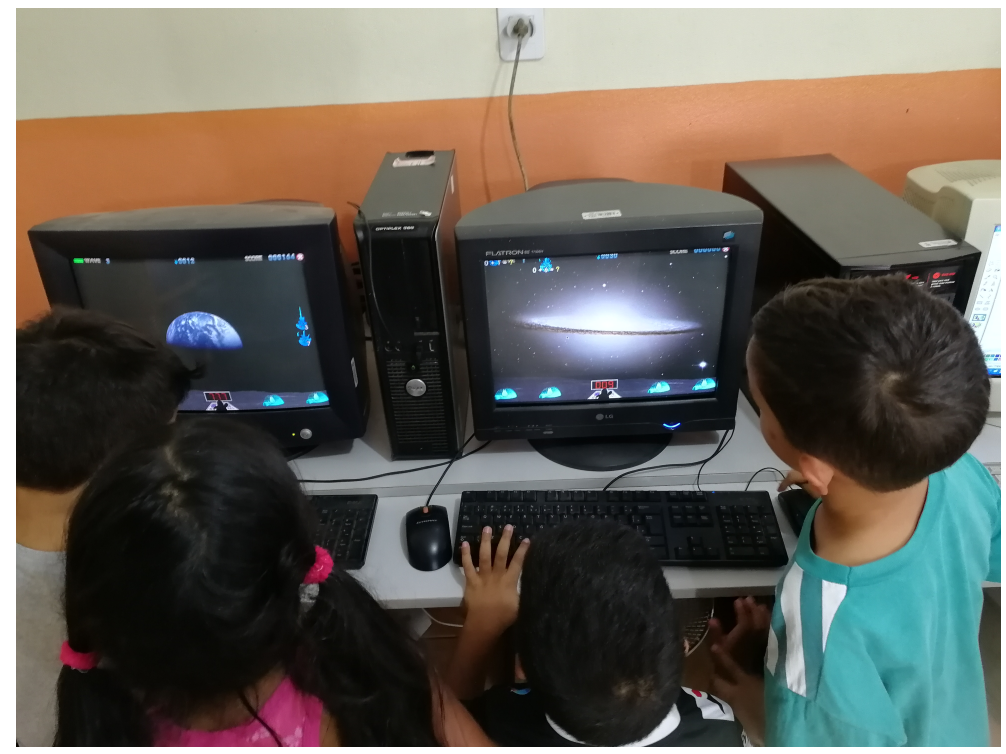

Figura 4. Crianças jogando Palavras Cadentes

No jogo das palavras, algumas crianças queriam jogar sozinhas e tentar acertar o mais rápido as teclas que apareciam na tela. Já outras, se uniram e procuraram juntas as teclas que tinham de ser pressionadas no teclado. Do outro lado da sala, no TuxPaint, os alunos foram sendo alternados de tempos em tempos. Alguns exploravam novas funções de desenho, como quadrados e círculos, enquanto outros usavam somente o pincel, assim como tiveram colegas que se uniram para desenhar juntos, porque assim, já que assim o tempo que poderiam ficar jogando era maior.

\subsection{Acompanhamento}

O acompanhamento pelo grupo discente envolvido no projeto foi realizado de diversas formas, seja presencial ou a distância. Criou-se um canal, através de e-mails e mensageiros, para que a direção da escola e os professores pudessem tirar dúvidas sobre o funcionamento do sistema operacional ou de aplicativos, bem como para reportar problemas detectados na utilização das ferramentas. Além disso, a cada duas semanas o grupo de discentes fez uma visita in loco na escola, para certificar-se que as atividades estão sendo desempenhadas da forma como foram planejadas.

Em todas as atividades realizadas com as crianças, fora possível perceber com clareza a realização pessoal e a alegria dos alunos de Educação Infantil ao lidar pela primeira vez com um computador. Além disso, os professores e coordenadores da escola ficaram entusiasmados com a ideia de trazer novas ferramentas de aprendizado. Reativar um recurso tão importante como a computação, que estava em situação precária pela falta de manutenção e de pessoal qualificado, também foi de grande valia para os estudantes da universidade envolvidos, que puderam ver o seu trabalho aplicado para o bem na sociedade e resolveram facilitar a realização de próximos projetos. 


\section{Conclusão}

O desenvolvimento e a análise deste estudo de caso tiveram como principal objetivo introduzir o saber computacional à crianças na sua fase escolar inicial, assim como o estímulo à criatividade e ao manuseio de ferramentas computacionais. Considera-se que quanto mais cedo estas crianças tiverem acesso às tecnologias de comunicação, maiores serão os benefícios alcançados. Para cumprir tal proposta foi realizada uma intervenção com 17 alunos, de cinco ou seis anos, da Escola Municipal Vila Jardim, de Santa Maria.

Não se trata de simplesmente inserir o computador na escola, mas sim de formar um aluno capaz de solucionar problemas, facilitar as suas atividades diárias e da escola, utilizando o computador, por meio de ferramentas previamente selecionadas através de revisão bibliográfica adequada. A escola transforma-se, desta forma, em uma possibilidade desse aluno aprender a buscar o conhecimento de que ele precisa, utilizando a tecnologia que ele dispõe no seu cotidiano ou no seu ambiente de trabalho.

Ao proporcionar os primeiros contatos com o computador e, especialmente, após a aplicação das atividades com os alunos, observou-se a crescente familiaridade com o computador e o manuseio do teclado e do mouse. Conseguiu-se identificar também a capacidade das crianças participarem das atividades, jogos e brincadeiras e demonstrarem, através dessas ações, o reconhecimento de números, letras e até de palavras.

Os resultados obtidos até o momento são as aptidões observadas nos alunos após o contato com a experiência proporcionada. Enquanto, antes, os alunos não apresentavam nenhum domínio em relação ao computador, após o desenvolvimento do projeto, as mesmas crianças demonstravam maior familiaridade com o manuseio das ferramentas utilizadas.

Como trabalhos futuros, será analisado ferramentas que possam dar estatísticas para os professores. Durante a realização da atividade notamos que seria válido criar um software de controle para os professores, onde eles poderiam ver a tela do aluno, controlar sites que podem ou não ser acessados, entre outras funcionalidades. Porém, no momento, a Escola Vila Jardim ainda não possui uma rede de computadores instalada, o que dificulta essa abordagem. Sendo assim, ferramentas offline poderão resolver provisoriamente o problema.

\section{Referências}

Bell, T., W. I. H. F. M. A. R. . M. J. (2011). Ensinando ciência da computação sem o uso do computador. Computer Science Unplugged ORG.

Brackmann, C. (2017). Desenvolvimento do pensamento computacional através de atividades desplugadas na educação básica. https://www.lume.ufrgs.br/handle/10183/172208. [Online; acessado em 12-042019].

Correia, W. F. (2013). O que é conservadorismo em educação? In CONJECTURA: filosofia e educação 18.2, p.78-90.

Costa, T., C. F. M. D. . d. S. W. (2016). A importância da computação para alunos do ensino fundamental: Ações, possibilidades e benefícios. In Anais do Workshop de Informática na Escola. Vol. 22, No. 1, p. 593, Sertão, PE, Brasil. 
Medeiros, C. B. (2011). Computação: o terceiro pilar. In Rev. USP, São Paulo, SP, Brasil.

Moran, J. M. (2009). A educação que desejamos: novos desafios e como chegar lá. In $4^{a}$ ed. Campinas: Papirus, São Paulo, SP, Brasil.

SBC (2018). Diretrizes para ensino de computação na educação básica. http://www.sbc.org.br/educacao/diretrizes-para-ensino-de-computacao-na-educacaobasica. [Online; acessado em 12-04-2019].

UFPR (2012). Linux educacional. https://linuxeducacional.c3sl.ufpr.br/LE5/index.html. [Online; acessado em 12-04-2019]. 